\title{
Optimalisasi Letter of Death Information melalui Redesain Form di RSIA Muhammaddiyah Kota Probolinggo
}

\author{
Sukma Surya Putri ${ }^{1}$, Dony S H Putra ${ }^{2}$, Hendro Prasetyo ${ }^{3}$, Rindy U. Maslicha ${ }^{2}$, Moh. Choirur Roziqin ${ }^{2}$ \\ IPT. Nusantara Medika Utama, Indonesia \\ ${ }^{2}$ Jurusan Kesehatan, Politeknik Negeri Jember, Indonesia \\ ${ }^{3}$ Jurusan Kebidanan, Poltekkes Kemenkes Malang, Indonesia \\ e-mail:dentistaputri@gmail.com
}

\begin{abstract}
Form of cause of death and death certificate is the recording of several diseases or a condition which is a series of a disease journey to death or accident, violence that causes injury and ends in death. This form is given to all types of causes of death. Based on preliminary surveys at RSIA Muhammdiyah, City of Probolinggo, officers did not write information about the formulas not in accordance with the guidelines for filling in the form of the cause of death and the BLKRI death certificate. The design of the cause of death form has not used the appropriate standard paper and there is no grouping of data regarding the type of cause of death of the patient. This study aims to redesign the form of cause of death and the form of a death certificate in RSIA Muhamaddiyah in the city of Probolinggo. The method used is qualitative with data collection techniques of observation, interviews, documentation and Brainstoming. Based on the results of the study it can be seen that the design of the cause of death form is not in accordance with the standards and user needs that can cause incompleteness in filling and obstructed the implementation of the action, therefore the cause of death and a new death certificate, is designed by considering 3 important aspects namely the physical aspects, anatomical aspects, and content aspects that are in accordance with the standards and needs of users. It is recommended that an evaluation of the cause of death form and a new death certificate be made to adjust to the needs of users who may change from time to time.
\end{abstract}

Keywords: form design, death certificate, cause of death.

\section{Pendahuluan}

Rumah Sakit sebagai sarana pelayanan kesehatan yang wajib menyelenggarakan rekam medis untuk mengoptimalkan pelayanan kesehatan yang diberikan. Rekam medis memiliki peran sebagai sumber informasi bagi pasien maupun pihak rumah sakit yang harus mendokumentasikan data pelayanan dan data identitas pasien secara lengkap, jelas, tertulis atau elektronik. Rekam medis dibuat segera setelah pasien menerima pelayanan agar keakuratan data terjaga dan kesinambungan informasi terjaga (Kemendagri dan Kemenkes RI, 2010).

Formulir rekam medis merupakan formulir yang berfungsi sebagai alat pengumpulan data yang berhubungan dengan pasien di rumah sakit. Analisis desain terhadap formulir perlu dilakukan untuk mengelola itemitem yang ada di formulir rekam medis berdasarkan tata letak, keterbacaan, dan kejelasan item sehingga terbentuk susunan item yang jelas, mudah dimengerti dan informatif terhadap pengguna (Hadmandho dalam Setiawan, 2016).

Formulir yang dirancang pada berkas rekam medis adalah formulir pencatatan kematian atau sering disebut dengan surat penyebab kematian. Pencatatan kematian adalah pencatatan kejadian kematian yang dialami oleh seseorang dalam register pada instansi pelaksana untuk pengolahan data kependudukan (Kemendagri dan Kemenkes RI, 2010).

Formulir penyebab kematian berfungsi untuk memantau pola mortalitas dan mendokumentasikan penyebab utama kematian, dengan hasil yang digunakan untuk menginformasikan kebijakan kesehatan dan meningkatkan strategi pencegahan dan pencatatan berita acara kematian seseorang (Kemendagri dan Kemenkes RI, 2010).

Berdasarkan hasil wawancara dengan petugas rekam medis belum terdapat formulir penyebab kematian dan surat keterangan kematian yang sesuai. Formulir penyebab kematian dan surat keterangan kematian yang ada belum sesuai dengan pedoman pengisian formulir penyebab kematian dan surat keterangan kematian. Badan batlingbangkes kemenkes RI (2010), menyebutkan surat keterangan kematian meliputi identitas, dasar diagnose, penyebab kematian dan diagnose penyebab kematian, formulir penyebab kematian. Surat keterangan kematian di RSIA Muhammadiyah Kota Probolinggo belum runtut dan belum lengkap, formulir penyebab kematin yang ada tidak dilakukannya monitoring dan 
evaluasi terhadap desain formulir penyebab kematian kematian dan tidak terdapat juknis pengisian.

Ketidaklengkapan pendokumentasian penyebab kematian di RSIA Muhamaddiyah Kota probolinggo dapat menyebabkan ketidaksinambungan informasi jenazah apabila penyebab kematian yang ada belum memenuhi standart sehingga akan berdampak terhadap mutu pelayanan kesehatan. Menurut Huffman (1999), formulir yang dirancang dengan kurag baik bisa menyebabkan pengumpulan data menjadi tidak memadai, dokumentasi menjadi lamban, informasi salah, duplikasi.

Menurut permasalahan diatas akan berdampak negatif ketidaklengkapan informasi yang ditulisakan pada formulir penyebab kematian, registrasi penyebab kematian. Pada Rumah Sakit, surat keterangan pelaporan kematian, dan akta kematian yang diberikan kepada keluarga pasien dan kepentingan pemakaman jenazah. Berdasarkan latar belakang tersebut, formulir penyebab kematian yang digunakan di RSIA Kota Probolinggo perlu ditambah kelengkapan berdasarkan aspek fisik, aspek anatomi dan aspek isi keterangan penyebab kematian terkait pada pasien yang terkandung dalam sebuah surat keterangan kematian sebagaimana diatur dalam Peraturan bersama Mendagri dan Menkes No.15 tahun 2010, nomor 162/MENKES/PB/I/2010, tentang pelaporan kematian dan Penyebab kematian. Sejalan dengan permasalahan tersebut, maka peneliti tertarik untuk meneliti tentang "Redesain Formulir Penyebab Kematian dan Surat Keterangan Kematian di RSIA Muhammaddiyah Kota Probolinggo".

Tujuan dari penelitian ini adalah mendesain ulang formulir penyebab kematian dan surat keterangan kematian di rumah sakit ibu dan anak Muhamaddiyah Kota Probolinggo. Manfaat dari penelitian ini adalah dihasilkannya desain formulir penyebab kematian dan surat keterangan kematian sesuai dengan kebutuhan pengguna dan standart pengisian formulir penyebab kematian dan surat keterangan kematian badan batlingbangkes kemenkes RI tahun 2010.

\section{Metode Penelitian}

Jenis penelitian yang digunakan adalah penelitian kualitatif. Lokasi penelitian dilaksanakan di Rumah Sakit Ibu dan Anak Muhamaddiyah Kota Probolinggo. Waktu penelitian dilaksanakan selama bulan Agustus sampai bulan November 2018.

\subsection{Metode Pengumpulan Data}

Penelitian menggunakan teknik pengumpulan data yang berbeda-beda untuk mendapatkan data dari sumber yang sama yaitu observasi, wawancara dan brainstorming. Tahap awal melakukan observasi formulir lama kemudian Wawancara kebutuhan dilakukan kepada 1 Kepala Rekam Medis, 1 petugas Pelayanan Medik dan 1 kepala perawat. Brainstorming untuk menentukan desain untuk memaparkan hasil desain formulir yang baru.

\subsection{Metode Analisis Data}

Data yang diperoleh akan dinarasikan secara deskriptif kualitatif dengan triangulasi.

\section{Hasil Dan Pembahasan}

\subsection{Identifikasi Aspek Fisik formulir penyebab kematian dan surat keterangan kematian}

Berdasarkan hasil wawancara dengan responden, diperoleh aspek fisik formulir berupa bahan kertas HVS/F4 70 gram, bentuk kertas persegi panjang dengan orientensi potrait, ukuran kertas $\mathrm{F} 4$ dengan panjang $33 \mathrm{~cm}$ dan lebar 21,59 cm, warna kertas penyebab kematian putih dan surat keterangan kematian putih, biru, kuning, merah dan hijau, jumlah kertas formulir penyebab kamtian satu lembar Surat keterangan kematian 4 lembar.

\subsection{Identifikasi Aspek Anatomi formulir Penyebab kematian dan Surat Keterangan Kematian}

Berdasarkan hasil wawancara dengan responden, kepala formulir (heading) kepala formulir yang digunakan mencakup identitas rumah sakit, serta logo rumah sakit RSIA Muhamaddiyah Kota Probolinggo. Pendahuluan (introduction) pendahulun di sesuaikan dengan judul formulir yaitu "Formulir penyebab kematian" dan lembar ke dua yaitu "surat keterangan kematian". Perintah (instruction) perintah pengisian formulir penyebab kematian dengan surat keterangan kematian menggunakan simbol $(*)$ untuk mengisi keterangan yang tidak digunakan, dan mencentang bagian yang sesuai dengan kondisi pasien. Isi (Body) meliputi margin (margins) disesuaikan dengan kolom pada isi formulir Spasi (spacings) disesuaikan dengan kebutuhan item pada formulir Garis (rules) menggunakan garis langsung vertikal dan horizontal untuk membatasi tiap-tiap item didalam formulir Jenis, huruf (type style) disamakan menggunakan huruf Times New Romman dengan ukuran 11pt untuk isi kecuali untuk judul disesuaikan dengan milik rumah sakit, Penutup (close) penutup tetap dengan format item tempat, tanggal tandatangan dokter penangung jawab dengan saksi 1 beserta 


\section{e-ISSN : 2579-5783}

nama terangnya masing-masing orang yang tanda tangan tangan pada formulir penyebab keatian dan surat keterangan kematian.

\subsection{Identifikasi Aspek Isi formulir penyebab kematian dan surat keterangan kematian}

Item data formulir penyebab kematian menurut pedoman pengisian surat keterangan kematian dan formulir penyebab kematian Badan Litbangkes Kemkes RI 2010 menggunakan istilah medis, pengelompokan, pengurutan, pembagian item yang sama rata, beberapa item formulirpenyebab kematian anatara lain identitas jenazah, penyebab kematian dan diagnosis penyebab kematian, sedangkan pada surat keterangan kematian terdiri dari identitas jenazah, identitas penerima jenazah dan dokter yang bertanggung jawab dan penyebab kematian.

Aspek isi yang merancang suatu formulir terdapat beberapa komponen yang meliputi kelengkapan item, pengelompokan, urutan, istialah, singkatam dan symbol. Berdasarkan hasil pengumpulan data yang dilakukan dengan cara observasi dan wawancara yaitu mengidentifikasi kebutuhan aspek isi pada formulir penyebab kematian dan surat keterangan kematian di RSIA Muhammaddiyah Kota Probolinggo sebagai berikut :

Pengelompokan item yang tercantum telah ditentukan dan disepakati yaitu:

1. Identitas rumah sakit

2. Identitas formulir

3. Sub judul pemberian informasi

4. Sub judul penyebab kematian

5. Penutup

Singkatan, singkatan yang digunakan di dalam formulir penyebab kematian dan surat kematian pada item waktu. Untuk item-item yang lain ditulis secara lengkap tanpa menggunakan singkatan. Simbol, symbol yang digunakan berupa tanda $(*)$ sebagai petunjuk yang merujuk pada cara pengisian yang ada pada bagian bawah formulir. Cara Pengisian, pengisian formulir penyebab kematian dan surat keterangan kematian di RSIA muhammaddiyah Kota probolinggo dilakukan dengan cara manual yaitu ditulis tangan oleh kepala pelayanan medik dan perawat yang memberikan diagnosis maupun tindakan pada jenazah.

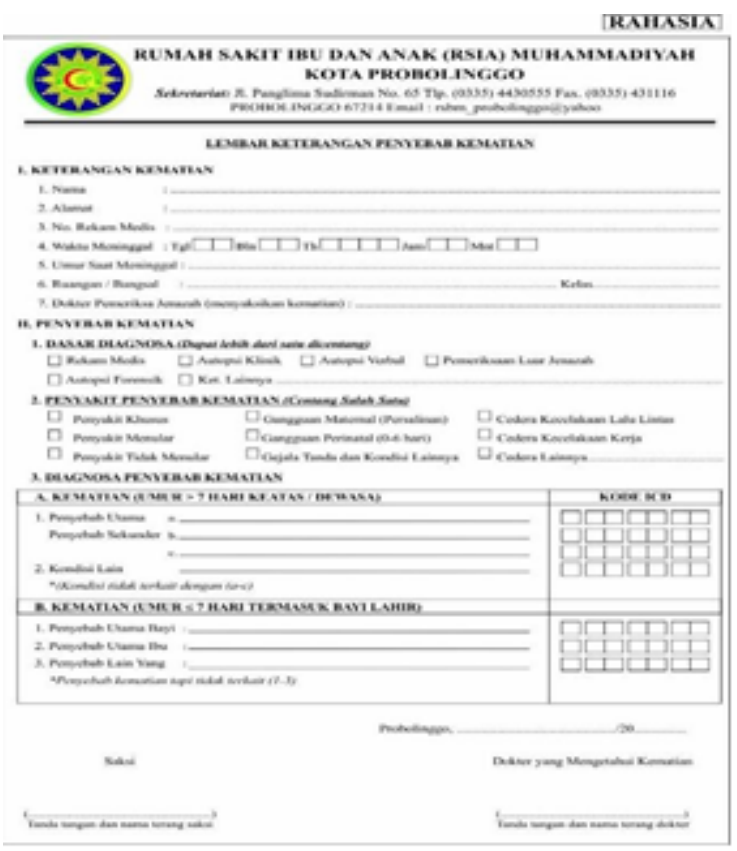

Gambar 1 Formulir Penyebab Kematian

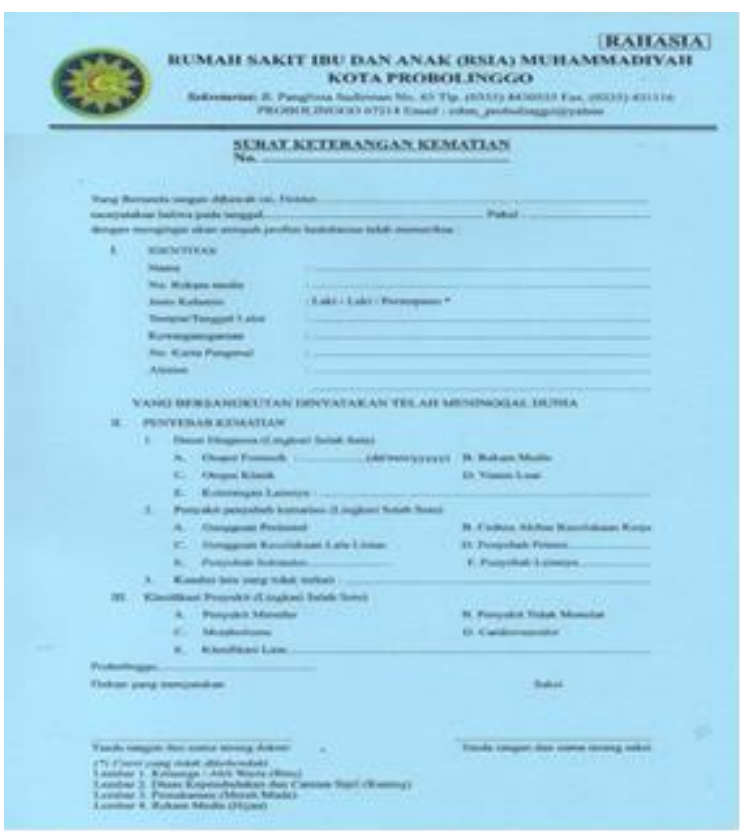

Gambar 2 Surat Keterangan Kematian untuk Keluarga atau Ahli Waris 


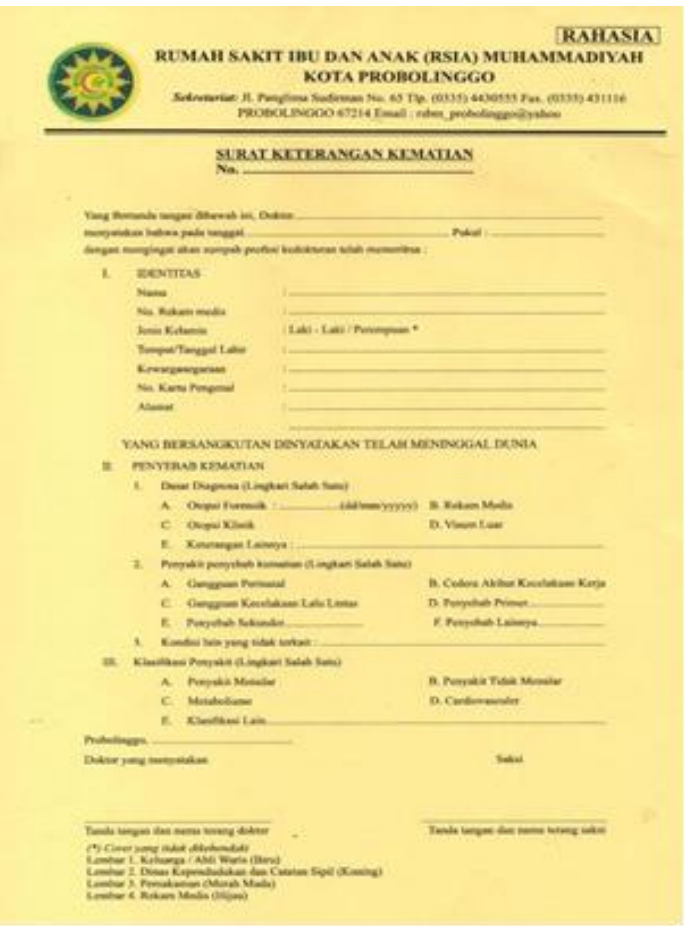

Gambar 3 Surat Keterangan Kematian untuk Dinas Kependudukan

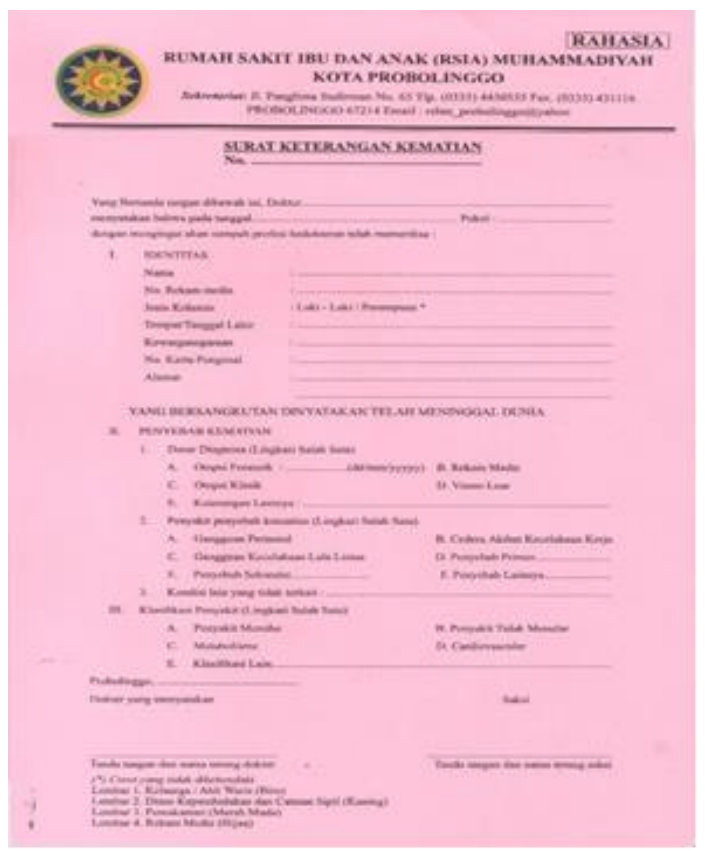

Gambar 4 Surat Keterangan Kematian untuk Pemakaman

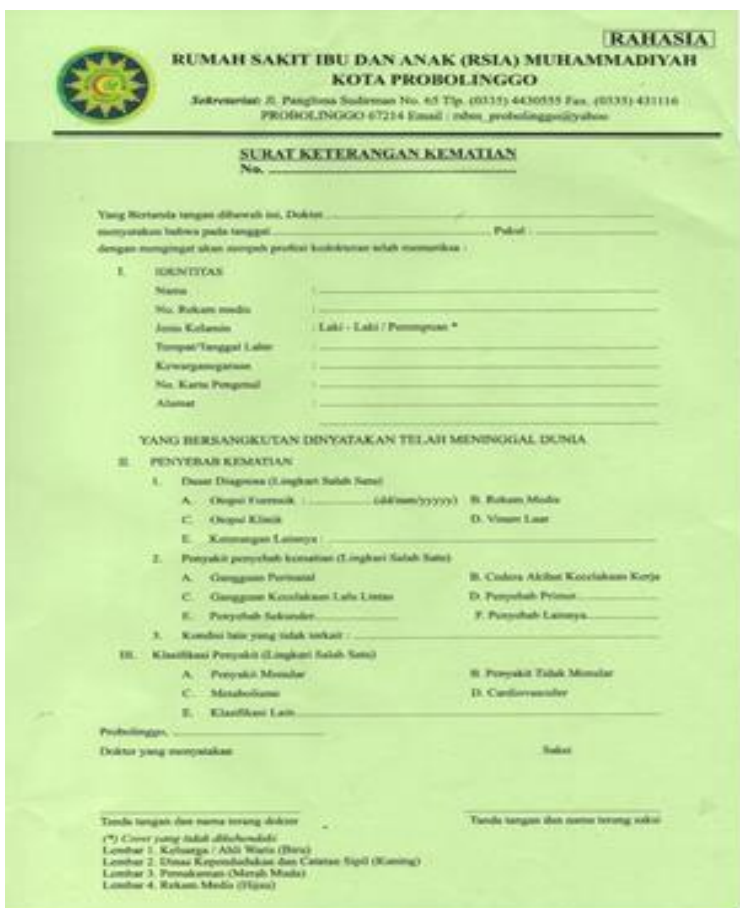

Gambar 5 Surat Keterangan Kematian untuk Rekam Medis

\section{Simpulan dan Saran 4.1 Simpulan}

Formulir lama memiliki beberapa hal yang tidak sesuai dengan teori yaitu jenis kertas yang digunakan setengah dari kertas A4, pendahuluan formulir yang berjudul Surat Keterangan Pemeriksaan (Kematian B), dan batas tepi yang digunakan pada formulir jauh dari standart yang telah ditetapkan. Isi minimal formulir penyebab kematian dan surat keterangan kematian tersebut harus menghasilkan informasi keterangan kematian, dasar diagnosa, penyakit penyebab kematian, diagnosa penyebab kematian.

\subsection{Saran}

Kepala Rekam Medis melakukan sosialisasi tentang formulir yang baru dibuat dan melakukan evaluasi secara berkala mengenai proses penggunaan formulir penyebab kematian dan surat keterangan kematian. Perlu adanya SOP pengisian formulir penyebab kematian dan surat keterangan kematian agar dokter penanggung jawab pasien mengisi secara lengkap.

\section{Daftar Pustaka}

Deharja, A., dan Swari, S. J. (2017). Desain Formulir Assesment Awal Medis 
ISSN : 2354-5852

e-ISSN : 2579-5783

Gawat Darurat Berdasarkan Standar Akreditasi Rumah Sakit Versi 2012 di Rumah Sakit Daerah Balung Jember. Seminar Hasil Penelitian 2017. Politeknik Negeri Jember.

Huffman, Edna. K. (1999). Health Information Management. Physicians Record Company. Illinois: Berwyn.

Kemendagri RI. (2009). Undang-Undang Republik Indonesia Nomor 44 tahun 2009 tentang Rumah Sakit. Jakarta: Deepartemen kesehatan RI.

Kemenkes RI. (2010). Pedoman pengisian surat keterangan kematian dan formulir keterangan penyebab kematian. Jakarta: Badan Litbangkes Kemkes RI.

Kemendagri dan Kemenkes. (2010). Peraturan bersama menteri dalam negeri dan menteri kesehatan nomor 15 tahun 2010 nomor 162/MENKES/PB/I/2010 tentang pelaporan kematian dan penyebab kematian. Jakarta: Mendegri dan Kemenkes.

Setiawan, D dkk. (2016). Perancangan formulir ringkasan masuk keluar dan resume medis elektronik di rsud dr. R. Soedarsono kota pasuruan tahun 2015. Jurnal Kesehatan Vol. 4. No. 1. JanuariApril 2016. Politeknik Negeri Jember. 